\title{
Chemical nature and structure of organic coating of quantum dots is crucial for their application in imaging diagnostics
}

This article was published in the following Dove Press journal:

International Journal of Nanomedicine

17 August 2011

Number of times this article has been viewed

\section{Rumiana Bakalova' \\ Zhivko Zhelev' \\ Daisuke Kokuryo' \\ Lubomir Spasov ${ }^{2}$ \\ Ichio Aoki' \\ Tsuneo Saga'}

'Molecular Imaging Center, National Institute of Radiological Sciences, Chiba, Japan; ${ }^{2}$ Medical Faculty, Sofia University, Sofia, Bulgaria
Correspondence: Rumiana Bakalova

Molecular Imaging Center,

National Institute of Radiological

Sciences, 4-9-I Anagawa,

Inage-ku, Chiba 263-8555, Japan

$\mathrm{Tel}+8 \mathrm{I} 432063274$

Fax +8I 432064682

Email bakalova@nirs.go.jp; ra_bakalova@ yahoo.com
Background: One of the most attractive properties of quantum dots is their potential to extend the opportunities for fluorescent and multimodal imaging in vivo. The aim of the present study was to clarify whether the composition and structure of organic coating of nanoparticles are crucial for their application in vivo.

Methods: We compared quantum dots coated with non-crosslinked amino-functionalized polyamidoamine (PAMAM) dendrimers, quantum dots encapsulated in crosslinked carboxyl-functionalized PAMAM dendrimers, and silica-shelled amino-functionalized quantum dots. A multimodal fluorescent and paramagnetic quantum dot probe was also developed and analyzed. The probes were applied intravenously in anesthetized animals for visualization of brain vasculature using two-photon excited fluorescent microscopy and visualization of tumors using fluorescent IVIS ${ }^{\circledR}$ imaging (Caliper Life Sciences, Hopkinton, MA) and magnetic resonance imaging.

Results: Quantum dots coated with non-crosslinked dendrimers were cytotoxic. They induced side effects in vivo, including vasodilatation with a decrease in mean arterial blood pressure and heart rate. The quantum dots penetrated the vessels, which caused the quality of fluorescent imaging to deteriorate. Quantum dots encapsulated in crosslinked dendrimers had low cytotoxicity and were biocompatible. In concentrations $<0.3 \mathrm{nmol}$ quantum dots $/ \mathrm{kg}$ bodyweight, these nanoparticles did not affect blood pressure and heart rate, and did not induce vasodilatation or vasoconstriction. PEGylation (PEG [polyethylene glycol]) was an indispensable step in development of a quantum dot probe for in vivo imaging, based on silica-shelled quantum dots. The non-PEGylated silica-shelled quantum dots possessed low colloidal stability in high-salt physiological fluids, accompanied by rapid aggregation in vivo. The conjugation of silica-shelled quantum dots with PEG1100 increased their stability and half-life in the circulation without significant enhancement of their size. In concentrations $<2.5 \mathrm{nmol} / \mathrm{kg}$ bodyweight, these quantum dots did not affect the main physiological variables. It was possible to visualize capillaries, which makes this quantum dot probe appropriate for investigation of mediators of vasoconstriction, vasodilatation, and brain circulation in intact animals in vivo. The multimodal silica-shelled quantum dots allowed visualization of tumor tissue in an early stage of its development, using magnetic resonance imaging. Conclusion: The present study shows that the type and structure of organic/bioorganic shells of quantum dots determine their biocompatibility and are crucial for their application in imaging in vivo, due to the effects of the shell on the following properties: colloidal stability, solubility in physiological fluids, influence of the basic physiological parameters, and cytotoxicity.

Keywords: quantum dot, organic shell, biocompatibility, in vivo imaging, two-photon excited fluorescent microscopy, magnetic resonance imaging

\section{Introduction}

One of the most attractive properties of quantum dots is their potential to extend the opportunities for fluorescent and multimodal imaging in vivo. The high quantum yield 
(over 50\%) and large excitation/emission Stokes shift (up to $300 \mathrm{~nm}$ ) allow minimization of tissue autofluorescence, especially when using quantum dots with deep-red or nearinfrared emission. The high intensity of multiphoton excited fluorescence of quantum dots and the possibility for timeresolved detection of fluorescence additionally increase the signal-to-background ratio in the living organism. Using quantum dots it is possible to visualize complex structures, cells, and even molecular targets at significantly greater depth in vivo, in comparison with that achieved by conventional organic fluorophores. ${ }^{1-3}$ The chemically functionalized surface of quantum dots, encapsulated in silica or other organic/bioorganic shells, also opens up an opportunity for development of multimodal probes, applicable in two or more imaging techniques, eg, magnetic resonance imaging/optical, positron emission tomography/optical, and positron emission tomography/magnetic resonance imaging/optical). ${ }^{1-4}$

In the development of quantum dot probes for in vivo multimodal imaging, it is necessary to follow a few rules. ${ }^{4}$ The most important are that the quantum dot nanocrystal has to be encapsulated in a bioinert and biocompatible shell to isolate it from the environment and to minimize its toxicity, and that the capsulated quantum dot nanocrystal has to be conjugated with biocompatible substances (usually polymers), decreasing its rate of accumulation in the liver and spleen and increasing the half-life in the bloodstream, facilitating access of quantum dots to the respective target and its visualization, and preventing opsonization and induction of a nonspecific immune response. ${ }^{5}$ The bioinert polymer shells may also increase the water solubility of quantum dots, which facilitates their excretion from the organism through renal filtration and decreases their toxicity. ${ }^{6,7}$

The idea of encapsulation of nanoparticles in biocompatible shells and their conjugation with biocompatible polymers emerged in the mid 1990s in the context of development of water-soluble paramagnetic and ferromagnetic nanoparticles for bioanalyses, ${ }^{8,9}$ as a result of earlier experience in the synthesis of biocompatible polymers for drug encapsulation and delivery. ${ }^{10-12}$ The earliest and most frequently used polymers for encapsulation of nanoparticles are polyethylene glycol (PEG) and dextran, as well as silica/silicagel shells. ${ }^{8,9}$ Later, biocompatible dendrimers and diblock/triblock copolymers were included in the composition. ${ }^{13,14}$

Dextran and PEG make the nanoparticles hydrophilic and increase their half-life in the circulation. However, in some cases, the dextran can induce an acute immune response as anaphylaxis. ${ }^{15}$ Currently, PEG or PEG derivatives are the polymers most commonly used to stabilize nanoparticles and to extend their half-life in the bloodstream due to the "sterically stabilizing effect of PEG" ${ }^{16}$ PEG forms a protective hydrophilic layer on the surface, preventing interaction between blood lipoproteins and cells (eg, macrophages) and significantly delays accumulation of the nanoparticles in the liver and spleen. ${ }^{5}$ This is an essential condition for development of contrast nanoprobes for imaging diagnostics, because it enables a longer scan time and accurate localization and visualization of the target of interest (tissues, cells, or expression of specific receptors or molecules). Therefore, PEGylation seems to be an indispensable step in the development of quantum dot probes for in vivo diagnostic imaging. The longer half-life of PEGylated quantum dots in the circulation also contributes to their effectiveness in target-specific diagnostic imaging. Penetration of quantum dots into the vasculature and their localization in target tissue is known as the "enhanced permeability and retention effect." There are also other polymers, including poly(oxazoline), poly(glycerol), and poly-N-vinylpyrrolidone, which have a sterically stabilizing action on nanoparticles. ${ }^{17,18}$

In the present study, we demonstrate the importance of the chemical nature and structure of the organic/bioorganic shells of quantum dots for their application in in vivo diagnostic imaging. Several quantum dot probes were developed and their biocompatibility was investigated and compared in experimental animals, using conventional physiological tests and two-photon excited fluorescent microscopy.

\section{Materials and methods}

\section{Quantum dots and quantum dot probes}

$\mathrm{CdSe} / \mathrm{ZnS}$ quantum dots were synthesized using the methods described by Peng and Peng ${ }^{19}$ and Zlateva et al. ${ }^{20}$ Nanocrystals were characterized by ultraviolet light/ultraviolet and fluorescent spectroscopy, X-ray analysis (Rigaku RINT-2100, Tokyo, Japan), and high-resolution transmission electron microscopy (JEOL JEM-3010, Tokyo, Japan).

The concentration of quantum dots was calculated using the method of Yu et al, with an extinction coefficient of $1 \times 10^{5} / \mathrm{cm} / \mathrm{M}^{21}$ Quantum dots were additionally coated with silica as described by Bakalova et al, ${ }^{22}$ polyamidoamine (PAMAM) dendrimers as described by Wu et $\mathrm{al}^{23}$ (with a slight modification of using the second-generation PAMAM-C12 dendrimer [Sigma-Aldrich, St Louis, MO] instead of octylaminemodified polyacrylic acid), and the second-generation PAMAM-C12 dendrimer (Sigma-Aldrich) crosslinked by a PAMAM-succinamic acid dendrimer (Sigma-Aldrich), with N-(3-dimethylaminopropyl)- $\mathrm{N}^{\prime}$-ethyl-carbodiimide hydrochloride used as a zero-length crosslinker. 
The conjugation of silica- or dendrimer-coated quantum dots with PEG was carried out using the method described in Hermanson. ${ }^{24}$ Methyl-PEG - NHS esters or methyl-PEG amines were used for conjugation with amino-functionalized or carboxy-functionalized quantum dots, respectively. The coated quantum dots and quantum dot-PEG conjugates were purified by spin ultrafiltration and kept at $4^{\circ} \mathrm{C}$. The amino-functionalized silica-shelled quantum dots were also conjugated with DOTA-phenyl isothiocyanate (DOTA-BnNCS/gadolinium, Macrocyclics Company, Dallas, TX) and PEGylated using methods described by Hermanson. ${ }^{24}$ The quantum dot/DOTA/PEG conjugates were purified by dialysis using a Slide-A-Lyzer ${ }^{\mathrm{R}}$ (Pierce Biotechnology Inc, Rockford, IL). The multimodal quantum dots were kept at $4^{\circ} \mathrm{C}$. Their $\mathrm{T}_{1}$ and $\mathrm{T}_{2}$ contrast properties were characterized using 7 Tesla magnetic resonance imaging (Kobelco, Kobe, Japan) ${ }^{25}$ All reagents used in this study were of analytical or high-pressure liquid chromatographic grade.

\section{Animals and experimental models}

Sprague-Dawley rats weighing $325 \pm 15 \mathrm{~g}$ were used for investigation of the biocompatibility of the quantum dot probes and their usefulness for fluorescent imaging in vivo. Balb6 nude mice ( $22 \pm \mathrm{g}$ ) were used for investigation of the usefulness of quantum dot probes for multimodal imaging of experimental tumors in vivo. Colon26 cells $\left(1 \times 10^{5}\right.$ in $10 \mu \mathrm{L}$ phosphate-buffered saline, $\mathrm{pH}$ 7.4) were inoculated subdermally in the left/right hindpaw. All measurements were performed five or ten days after inoculation, when the tumor was $1-2 \mathrm{~mm}$ or $5-6 \mathrm{~mm}$ in size, respectively.

All experiments were conducted in accordance with the guidelines of the Physiological Society of Japan and were approved by the Animal Care and Use Committee of the National Institute of Radiological Sciences, Chiba, Japan.

\section{Two-photon imaging of brain circulation in vivo}

The rat was anesthetized with isoflurane (Abbott, Tokyo, Japan) 4\% for induction, 2\% for surgery, and 1.4\% during measurements. Tracheal intubation was performed, and the femoral vein was catheterized for drug administration. The tail artery was catheterized for blood pressure monitoring and blood sampling. The rat was fixed in a stereotactic frame, the parietal bone was thinned to translucency over the somatosensory cortex $(3 \mathrm{~mm} \times 3 \mathrm{~mm})$, and the dura was kept intact. Body temperature was maintained at $37^{\circ} \mathrm{C}$, and systemic arterial blood pressure was periodically monitored at the tail artery. Heart rate and end-tidal gas levels were monitored continuously. To visualize the brain microcirculation, the quantum dot probe was injected (intravenously as a single dose, with an injected volume of $0.3 \mathrm{~mL}$, containing different quantum dot concentrations), and the brain area was excited by an $810 \mathrm{~nm}$ pulse laser (Maitai HP, Spectra-Physics, Irvine, CA) under microscope (SP5, Leica) equipped with a $10 \times$ objective lens ( 0.30 numerical aperture). The vessel diameter was then determined by measuring the width of the vessel image projected across the $15 \mathrm{Z}$ images (up to nearly $0.3 \mathrm{~mm}$ from the cortical surface) in each vessel segment. The experimental scheme is shown in Supplementary Figure S1.

\section{IVIS ${ }^{\circledR}$ imaging in vivo}

The mouse was anesthetized with 1.5\% isoflurane (Abbott). The tail veil was catheterized for drug administration and the mouse was fixed in the camera of the IVIS ${ }^{\circledR}$ imaging system (Caliper Life Sciences, Hopkinton, MA). Body autofluorescence was registered using an excitation filter of $450 \pm 30 \mathrm{~nm}$ and an emission filter of $650 \mathrm{~nm}$. The quantum dot probe was injected (intravenously as a single dose of $1.6 \mathrm{nmol} /$ $\mathrm{kg}$ bodyweight, $100 \mu \mathrm{L}$ volume) and body fluorescence was registered at a series of time intervals over 90 minutes. The data were analyzed by Living Image ${ }^{\mathrm{R}}$ software (version 2.50.1, Xenogen Corporation, Alameda, CA).

\section{Magnetic resonance imaging in vivo}

Magnetic resonance imaging measurements were performed on a 7.0 Tesla horizontal magnet (Kobelco and Jastec, Tokyo, Japan) interfaced to a Bruker Avance I console (Bruker BioSpin, Karlsruhe, Germany) and controlled with ParaVision 4.0.1 (Bruker BioSpin). The animal (a Balb6 mouse) was anesthetized using isoflurane $1.5 \%$ and held in a body cradle (Rapid Biomedical, Rimpar, Germany) in the prone position. Rectal temperature was continuously monitored and automatically controlled at $36.5 \pm 0.5^{\circ} \mathrm{C}$ using a nonmagnetic temperature probe (FOT-M and FTI-10, FISO Technology, Olching, Germany) and an electric temperature controller (E5CN, Omron, Kyoto, Japan) during magnetic resonance imaging measurements. The tail vein was catheterized using a polyethylene tube (PE-10, Becton-Dickinson, Franklin Lakes, NJ) for drug administration. The mouse was then placed in a proton volume radiofrequency resonator (Bruker BioSpin) with a surface radiofrequency receiver (Rapid Biomedical) previously warmed using a body temperature controller (Rapid Biomedical). The resonator units, including the mouse, were placed in the magnet bore. Magnetic resonance imaging was performed using the following parameters: $\mathrm{T}_{1}$-weighted 
imaging; spin echo sequence with fat suppression preparation pulse; repetition time $400 \mathrm{msec}$; echo time $9.574 \mathrm{msec}$; field of view $32 \times 32 \mathrm{~mm}$; matrix size $256 \times 256$; slice thickness $1.0 \mathrm{~mm}$; spatial resolution $125 \times 125 \times 1000 \mu \mathrm{m}$; four averages; and a total scan time of six minutes and 50 seconds. The magnetic resonance images were obtained before and after injection of the quantum dot probe (intravenously, single dose of $1 \mu \mathrm{mol} / \mathrm{kg}$ bodyweight, $100 \mu \mathrm{L}$ volume) using the same gain level. The magnetic resonance imaging data were reconstructed by ParaVision and analyzed using MRVision image analysis software (version 1.5.8, MRVision Co, Winchester, MA).

\section{Flow-cytometric cell viability assay}

The cell suspension $\left(5 \times 10^{5}\right.$ cells $\left./ \mathrm{mL}\right)$ was incubated with quantum dots at a series of concentrations over 24 hours in a humidified atmosphere and washed three times with phosphate-buffered saline. Five hundred microliters of the same cell suspension was incubated with $20 \mu \mathrm{L}$ of propidium iodide (Sigma-Aldrich) for 10 minutes at room temperature. The cells were washed three times by phosphate-buffered saline, using centrifugation $(1000 \times \mathrm{g} / 10$ minutes $)$, and finally resuspended in $500 \mu \mathrm{L}$ of phosphate-buffered saline. The propidium iodide entered the dead cells and did not enter the live ones. The cell suspension was subjected to flow cytometric analysis, using a Beckman Coulter-Epics XL flow cytometer (Fullerton, CA), operated in accordance with the manufacturer's recommendations after fine adjustments for optimization of the measurements. The forward-scattered and side-scattered parameters were adjusted to accommodate the inclusion of viable and dead cells within the acquisition data. No cells were excluded from the analysis, and about 10,000 cells were counted. Data were collected and analyzed using XL System II software.

The results were presented as a dot plot of cell fluorescence with quadrant markers drawn to distinguish viable (nonlabeled) and dead (propidium iodide-labeled) cells (Figure 1).

Cell viability after treatment with quantum dots was calculated by the following equation:

$$
\text { cell viability }(\%)=\frac{B_{p}}{B_{p}+\left(D_{p}-D_{c}\right)} \times 100
$$

where $B_{p}$ is the number of viable cells in quadrant $B$ of the sample, treated by quantum dots; $\mathrm{D}_{\mathrm{p}}$ is the number of dead cells in quadrant $\mathrm{D}$ of the sample, treated by quantum dots; $\mathrm{D}_{\mathrm{c}}$ is the number of dead cells in quadrant $\mathrm{D}$ of the control

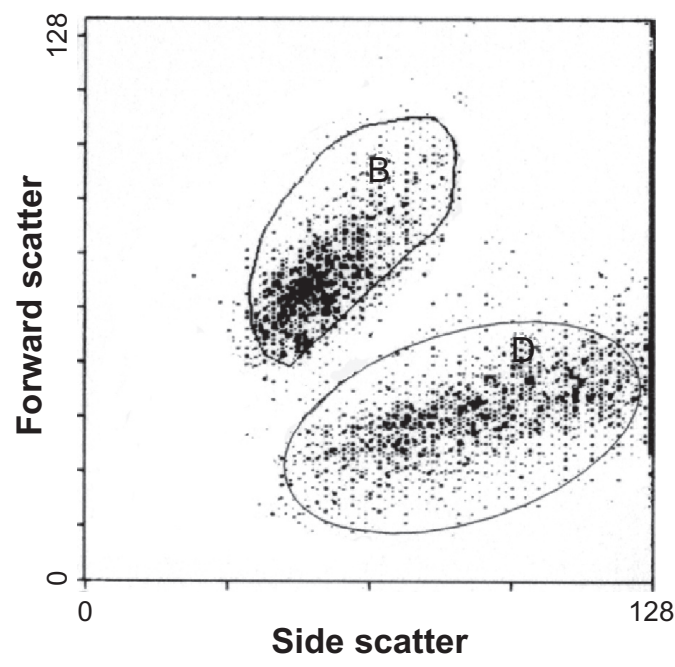

Figure I A flow cytometric histogram of cell fluorescence with quadrant markers, drawn to distinguished viable (nonlabeled) from dead (propidium iodide-labeled) cells. Quadrant B shows viable cells and quadrant $D$ shows dead cells.

sample (not treated with quantum dots). Quantum dot ${ }^{485}$ probes were used in all flow cytometric analyses.

\section{Mitochondrial potential assay}

The mitochondrial potential was analyzed using the method described by Wong and Cortopassi ${ }^{26}$ using 48-well plates and tetramethylrhodamine ethyl ester as a fluorescent marker (TMRE, Immunochem Diagnostic Technologies Ltd, Truro, Nova Scotia). Briefly, $50 \mathrm{nM}$ of TMRE was added to $500 \mu \mathrm{L}$ of cell suspension $\left(1 \times 10^{6}\right.$ cells $\left./ \mathrm{mL}\right)$, and the fluorescence was measured using a BioRad microplate reader (BioRad Laboratories, Hercules, CA) equipped with a temperature controller. The temperature of the cell suspension was maintained at $37^{\circ} \mathrm{C}$. The fluorescence of each well was detected over two cycles every five minutes at $\lambda_{\text {ex }}=540 \mathrm{~nm}$ and $\lambda_{\text {em }}=575 \mathrm{~nm}$. A quantum dot ${ }^{485}$ probe was added to each well and the fluorescence detection was continued over seven cycles every five minutes. The data were normalized to the autofluorescence of the quantum dot and the cell suspension was not treated with TMRE (baseline fluorescence).

\section{Results and discussion Biocompatibility of dendrimer-shelled quantum dots}

Two quantum dot probes were developed using PAMAM dendrimers as an organic shell (Figure 2). For the first probe, a quantum dot nanocrystal was coated with a noncrosslinked second generation PAMAM C12 dendrimer). The carbohydrate chains (C12) of dendrimer interact with 


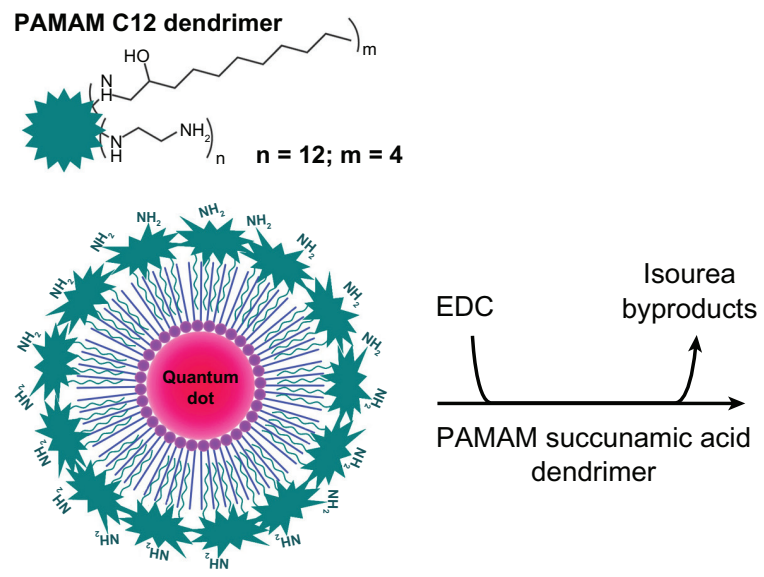

QD coated with PAMAM-C12 dendrimers

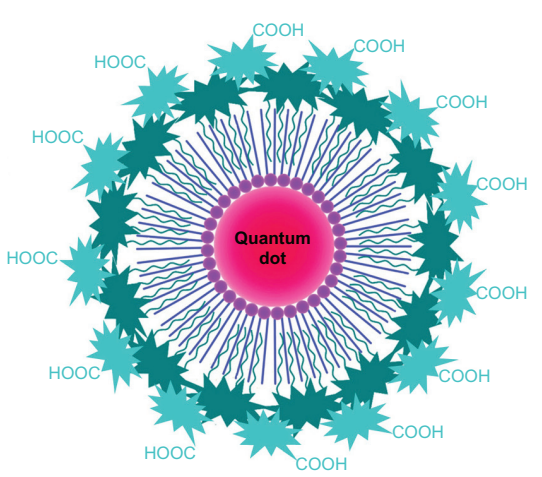

QD coated with cross-linked PAMAM-C12 dendrimer (QD, capsulated in dendrimers)

Figure 2 Model structure of quantum dot probes, consisting of CdSe/ZnS quantum dots coated with non-crosslinked PAMAM dendrimers or encapsulated in crosslinked PAMAM dendrimers.

Abbreviations: PAMAM, polyamidoamine; EDC, I-ethyl-3(3-dimethylamino propyl)-carbodiimide; QD, quantum dot.

the hydrophobic coordinating ligands of the quantum dot via van der Waals interactions. As a result, the surface of this dendrimer-coated quantum dot was amino-functionalized and positively charged. The second quantum dot probe was developed from the first one through a crosslink between the surface amino groups of the PAMAM C12 dendrimer and the carboxyl groups of the second-generation PAMAM succinamic acid dendrimer, with formation of amide bonds (Figure 2). Thus, in the second quantum dot probe, the nanocrystal was capsulated in crosslinked PAMAM dendrimers, and the surface of the nanoparticles was carboxylfunctionalized and negatively charged.

The zeta potential of amino-functionalized dendrimercoated quantum dots was about $+7.0 \mathrm{mV}$ at $\mathrm{pH} 7.4$, and for carboxyl-functionalized dendrimer-capsulated quantum dots was about $-18.7 \mathrm{mV}$ at $\mathrm{pH}$ 7.4. Both measurements were made in phosphate-buffered saline. Both quantum dot probes were characterized with excellent solubility in distilled water, and low-salt and high-salt physiological fluids (eg, buffers, saline solution, phosphate-buffered saline, cell cultured medium, plasma). The quantum dot probes were used for in vivo fluorescent imaging of the brain circulation in anesthetized rats, using two-photon excited fluorescent microscopy.

Figure 3 shows two-photon excited fluorescent images of brain vasculature after intravenous injection of dendrimer-coated quantum dots ${ }^{525}$. The images were obtained at $\lambda_{\mathrm{ex}}=810 \mathrm{~nm}$ with an emission filter of $525 \pm 50 \mathrm{~nm}$, in a horizontal scanning plane at a depth of $150 \mu \mathrm{m}$ from the surface of the skull.
In the case of quantum dots coated with non-crosslinked dendrimers, turbidity of the images increased during the scan time (Figure 3A). This impeded measurement and calculation of the average diameter of the arterioles and venuoles. Concentration of the injected quantum dot probe

A CdSe/ZnS QD, capsulated in PAMAM dendrimers $(0.3 \mathrm{nmol} / \mathrm{kg}$ bodyweight $)$

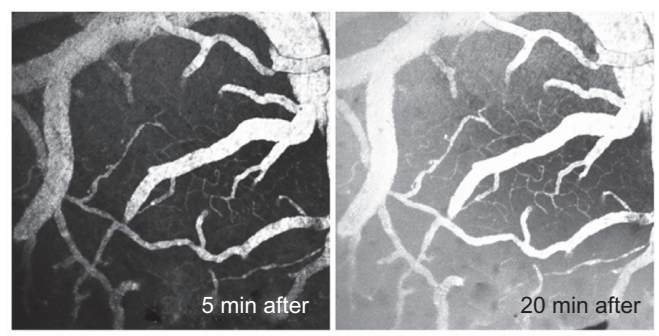

B CdSe/ZnS QD, capsulated in crosslinked dendrimers ( $0.3 \mathrm{nmol} / \mathrm{kg}$ bodyweight)

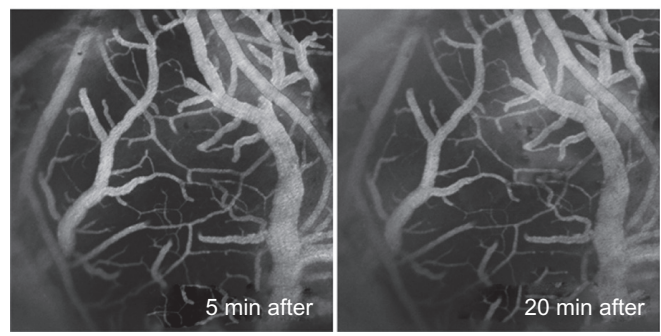

Figure 3 Two-photon excited fluorescent images of brain vasculature in horizontal planes (at $150 \mu \mathrm{m}$ depth from brain surface) after intravenous injection of $Q D^{525}$ (coated with non-crosslinked PAMAM dendrimers [A] or capsulated in crosslinked dendrimers $[\mathbf{B}]$ in the anesthetized rat).

Notes: All images were obtained at $\lambda_{\mathrm{ex}}=810 \mathrm{~nm}$ and a mean laser power of about 2.7 W. Detectors: filter/band-pass $525 / 50 \mathrm{~nm}$ (via $560 / 10 \mathrm{~nm}$ beam splitter). Abbreviations: PAMAM, polyamidoamine; QD, quantum dot. 
Table I Physiological characteristics of rats before and after intravenous injection of QDs (coated with noncrosslinked PAMAM dendrimers)

\begin{tabular}{llll}
\hline Parameters & $\begin{array}{l}\text { Before } \\
\text { injection }\end{array}$ & $\begin{array}{l}\text { About 20 minutes } \\
\text { after injection }\end{array}$ & P value \\
\hline $\begin{array}{l}\text { Mean arterial blood } \\
\text { pressure }(\mathrm{mmHg})\end{array}$ & $102.5 \pm 2.5$ & $75.5 \pm 7.1$ & $<0.05$ \\
$\begin{array}{l}\text { Heart rate } \\
\text { (beats per minute) }\end{array}$ & $378 \pm 29$ & $310 \pm 15$ & $<0.05$ \\
$\begin{array}{l}\text { Mean diameter of } \\
\text { detected arteries }(\mu \mathrm{m})\end{array}$ & $28 \pm 9$ & $\begin{array}{l}35 \pm 10 \\
\text { (vasodilatation) }\end{array}$ & $<0.05$ \\
$\begin{array}{l}\text { Mean diameter of } \\
\text { detected veins }(\mu \mathrm{m})\end{array}$ & $42 \pm 23$ & $\begin{array}{l}45 \pm 18 \text { (slight } \\
\text { vasodilatation) }\end{array}$ & NS \\
\hline
\end{tabular}

Notes: Means \pm standard deviations from six independent experiments. QD concentration $0.3 \mathrm{nmol} / \mathrm{kg}$ bodyweight.

Abbreviations: QD, quantum dot; NS, not significant; PAMAM, polyamidoamine.

was $0.3 \mathrm{nmol}$ quantum dots/kg bodyweight. Increasing the concentration also made it difficult to define the outlines of the large blood vessels (arteries and veins). Intravenous injection of this quantum dot probe changed the basic physiological characteristics of the animal (Table 1). Mean arterial blood pressure and heart rate decreased, accompanied by vasodilatation.

PAMAM C12 dendrimers (without quantum dots) had similar effects (see Table $\mathrm{S} 1$ for supplementary information). Even low concentrations of the PAMAM C12 dendrimer $(0.1 \mathrm{nmol} / \mathrm{kg}$ bodyweight injected intravenously in the rat) decreased blood pressure and heart rate and induced vasodilatation.

In the case of quantum dots encapsulated in crosslinked dendrimers, the turbidity of the fluorescent images was negligible (Figure 3B). The images did not change during the scan time. The large and small blood vessels were well outlined and it was easy to measure their average diameter. This quantum

Table 2 Physiological characteristics of rats before and after intravenous injection of QDs (encapsulated in crosslinked PAMAM dendrimers)

\begin{tabular}{lcll}
\hline Parameters & $\begin{array}{l}\text { Before } \\
\text { injection }\end{array}$ & $\begin{array}{l}\text { About 20 minutes } \\
\text { after injection }\end{array}$ & $\boldsymbol{P}$ value \\
\hline $\begin{array}{l}\text { Mean arterial blood } \\
\text { pressure }(\mathrm{mmHg})\end{array}$ & $96.8 \pm 4.9$ & $100.5 \pm 8.4$ & NS \\
$\begin{array}{l}\text { Heart rate (beats } \\
\text { per minute) }\end{array}$ & $340 \pm 21$ & $336 \pm 23$ & NS \\
$\begin{array}{l}\text { Mean diameter of } \\
\text { detected arteries }(\mu \mathrm{m})\end{array}$ & $23 \pm 10$ & Constant & NS \\
$\begin{array}{l}\text { Mean diameter of } \\
\text { detected veins }(\mu \mathrm{m})\end{array}$ & $41 \pm 20$ & Constant & NS \\
\hline
\end{tabular}

Notes: Means \pm standard deviations from six independent experiments. QD concentration $0.3 \mathrm{nmol} / \mathrm{kg}$ bodyweight.

Abbreviations: QD, quantum dot; NS, not significant; PAMAM, polyamidoamine.
Table 3 Effect of CdSe/ZnS QD ${ }^{485}$ (coated with noncrosslinked PAMAM dendrimers) on cell viability in vitro (\% from control)

\begin{tabular}{|c|c|c|c|c|c|}
\hline $\begin{array}{l}\text { Cell } \\
\text { line }\end{array}$ & $\begin{array}{l}10 \mathrm{nM} \\
\mathrm{QD}\end{array}$ & $\begin{array}{l}50 \mathrm{nM} \\
\mathrm{QD}\end{array}$ & $\begin{array}{l}100 \mathrm{nM} \\
\text { QD }\end{array}$ & $\begin{array}{l}200 \mathrm{nM} \\
\text { QD }\end{array}$ & $\begin{array}{l}500 \mathrm{nM} \\
\text { QD }\end{array}$ \\
\hline Jurkat & $99 \pm 7$ & $97 \pm 5$ & $62 \pm 5$ & $30 \pm 7$ & $21 \pm 4$ \\
\hline K562 & $101 \pm 6$ & $98 \pm 9$ & $62 \pm 9$ & $37 \pm 5$ & $16 \pm 3$ \\
\hline A549 & $103 \pm 9$ & $101 \pm 5$ & $65 \pm 7$ & $39 \pm 5$ & $28 \pm 5$ \\
\hline HeLa & $99 \pm 3$ & $100 \pm 5$ & $60 \pm 8$ & $32 \pm 3$ & $20 \pm 4$ \\
\hline
\end{tabular}

Notes: The cell suspension $\left(5 \times 10^{5}\right.$ cells $\left./ \mathrm{mL}\right)$ was incubated with QDs over 24 hours in a humidified atmosphere, and cell viability was analyzed by flow cytometry. Cell viability in the absence of QD was considered 100\% (control). The data are mean \pm standard deviation from six independent experiments.

Abbreviations: $\mathrm{QD}$, quantum dot; PAMAM, polyamidoamine.

dot probe did not affect mean arterial blood pressure or heart rate (Table 2) even one hour after injection.

The dendrimer-encapsulated quantum dots were also PEGylated using PEG1100. However, PEGylation did not significantly increase the half-life of the quantum dots in the

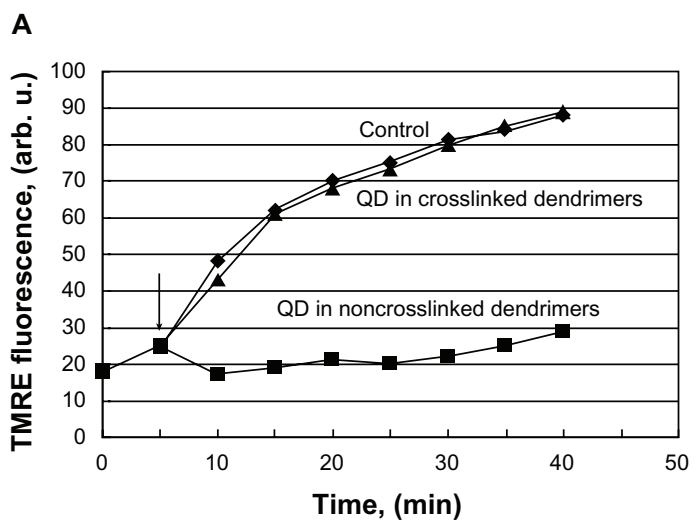

B

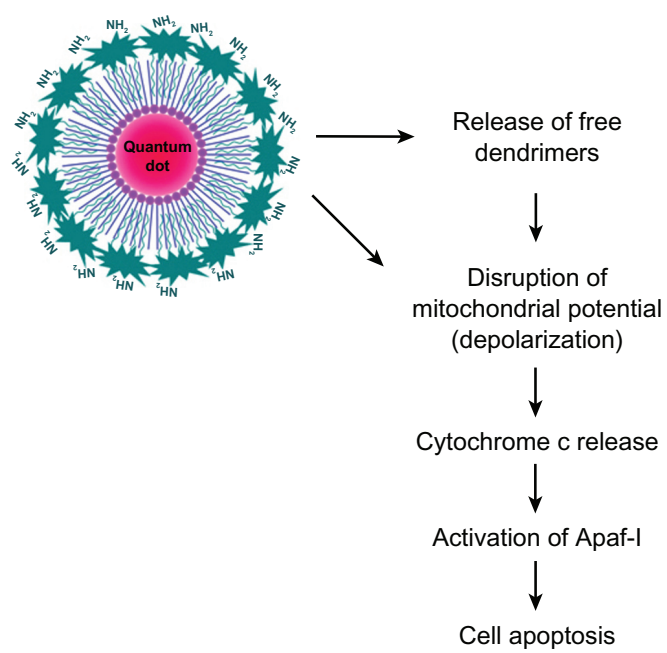

Figure 4 (A) Dynamics of tetramethylrhodamine ethyl ester (TMRE) fluorescence of Jurkat cells in the absence (control) or presence of dendrimer-coated QD ${ }^{485}$ $100 \mathrm{nM}$. (B) Hypothetical mechanism of cytotoxicity of QD, coated with noncrosslinked polyamidoamine dendrimers.

Abbreviations: Apaf-I, apoptotic peptidase-activating factor I; QD, quantum dot. 


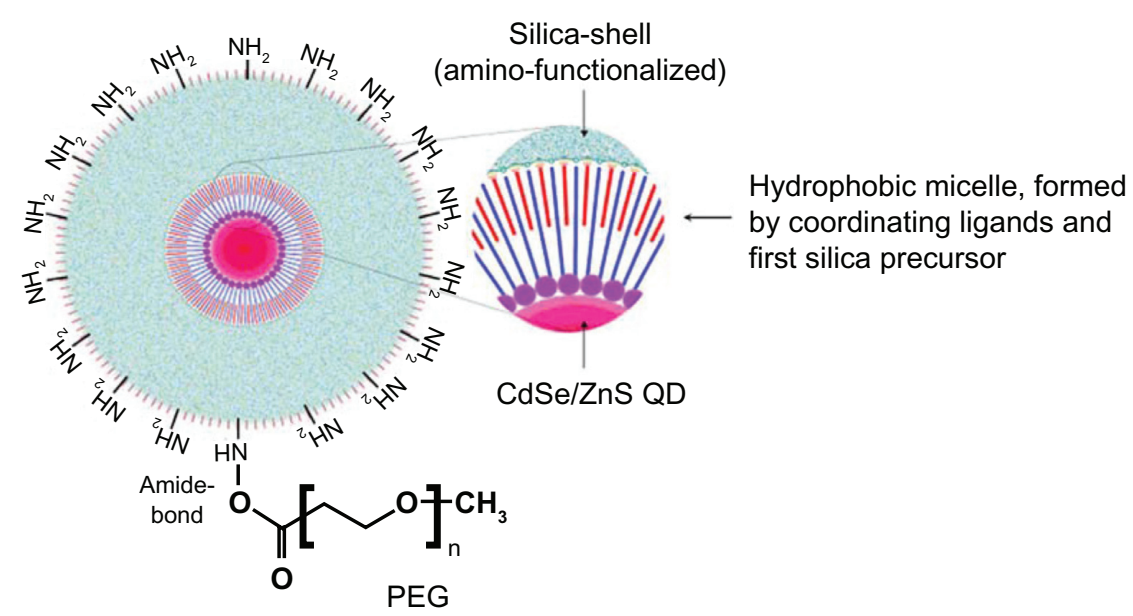

Figure 5 Model structure of QD probe, consisting of silica-shelled QD conjugated with PEG. ${ }^{48}$

Note: Reprinted with permission from Zhelev Z, Ohba H, Bakalova R. Single quantum dot-micelles coated with silica shell as potentially non-cytotoxic fluorescent cell tracers. J Am Chem Soc. 2006;128:6324-6325. Copyright 2006 American Chemical Society.

Abbreviations: QD, quantum dot; PEG, polyethylene glycol.

brain circulation (elimination half-life was approximately 65 minutes for the non-PEGylated probe and approximately 70 minutes for the PEGylated probe), and is not an obligatory step for dendrimer-coated quantum dots.

These results demonstrate the importance of the nature and structure of the organic shell of quantum dots for their application in vivo. The positively charged quantum dot probe, consisting of quantum dots coated with non-crosslinked PAMAM dendrimers, caused side effects in vivo, accompanied by poor quality of the fluorescent images. This quantum dot probe is not appropriate for visualization of the brain vasculature and investigation of the biological phenomena related to the brain circulation. Turbidity of the images after injection of this probe could be explained by its transepithelial and transendothelial penetration. Kitchens et $\mathrm{al}^{27}$ have reported that the cationic PAMAM dendrimers (generation 0-4) are highly permeable for epithelial and endothelial cells and penetrate easily and rapidly through the blood vessels. This property of PAMAM dendrimers is widely used in development of drug delivery systems. ${ }^{28-31}$ Quantum
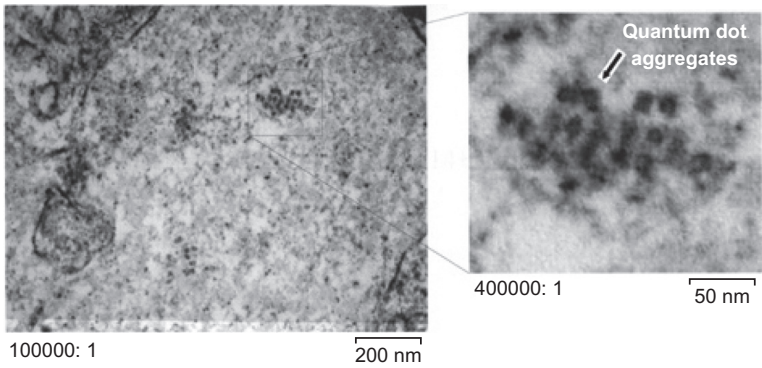

Figure 6 Electron micrographs of nasal mucosa one day after intranasal inoculation of amino-functionalized silica-shelled quantum dots (dissolved in distilled water, 30 drops per animal, single dose).

Abbreviation: QD, quantum dot. dots coated with noncrosslinked PAMAM dendrimers were also cytotoxic (Table 3), and their application for in vitro imaging analyses was limited.

PAMAM C12 dendrimers had similar cytotoxic effects in vitro, while positively charged water-soluble quantum dots, prepared by direct surface exchange of hydrophobic coordinating ligands with cysteamine, were noncytotoxic in concentrations up to $500 \mathrm{nM}$ and at 24 hours' incubation time (see Tables S2 and S3 for supplementary information). This is in agreement with data reported in 2004 by Derfus et al. ${ }^{32}$ The authors found that noncoated $\mathrm{CdSe} / \mathrm{ZnS}$ quantum dots were not cytotoxic in concentrations up to $1 \mu \mathrm{M}$, even after ultraviolet irradiation.

The encapsulation of quantum dots in negatively charged crosslinked dendrimers decreased their cytotoxicity and abolished the side effects on physiological variables in vivo. The encapsulated quantum dots did not show cytotoxicity in concentrations up to $500 \mathrm{nM}$ (data
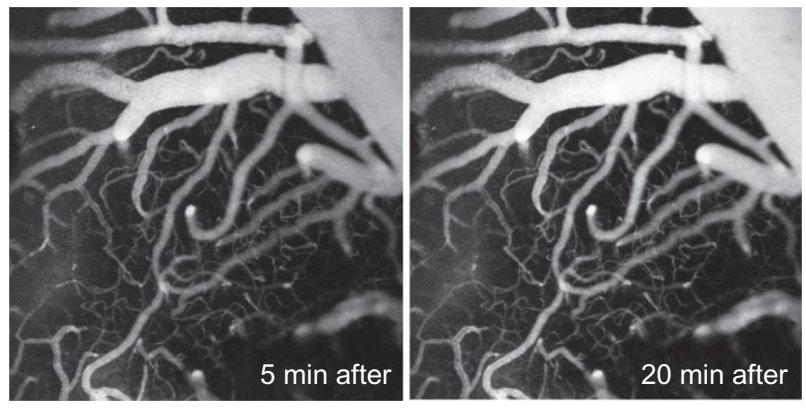

Figure 7 Two-photon excited fluorescent images of brain vasculature in horizontal planes (at $150 \mu \mathrm{m}$ depth from the brain surface) after intravenous injection of PEG I I00-grafted silica-shelled QD ${ }^{525}$ (2.5 nmol/ $/ \mathrm{kg}$ bodyweight) in the anesthetized rat. The images were obtained at $\lambda_{\mathrm{ex}}=810 \mathrm{~nm}$ and a mean laser power of about 2.7 W. Detectors: filter/band-pass: $525 / 50 \mathrm{~nm}$ (via a $560 / 10 \mathrm{~nm}$ beam splitter). Abbreviations: QD, quantum dot; PEG, polyethylene glycol. 
Table 4 Physiological characteristics of rats before and after intravenous injection of PEG I I00-grafted silica-shelled QDs

\begin{tabular}{lcll}
\hline Parameters & $\begin{array}{l}\text { Before } \\
\text { injection }\end{array}$ & $\begin{array}{l}\text { About 20 minutes } \\
\text { after injection }\end{array}$ & P value \\
\hline $\begin{array}{l}\text { Mean arterial blood } \\
\text { pressure }(\mathrm{mmHg})\end{array}$ & $96.2 \pm 5.4$ & $95.3 \pm 12.8$ & NS \\
$\begin{array}{l}\text { Heart rate } \\
\text { beats per minute) }\end{array}$ & $320 \pm 55$ & $345 \pm 5 \mathrm{I}$ & NS \\
$\begin{array}{l}\text { Mean diameter of } \\
\text { detected arteries }(\mu \mathrm{m})\end{array}$ & $24 \pm 9$ & Constant & NS \\
$\begin{array}{l}\text { Mean diameter of } \\
\text { detected veins }(\mu \mathrm{m})\end{array}$ & $41 \pm 22$ & Constant & NS \\
\hline
\end{tabular}

Notes: Means \pm standard deviations from six independent experiments. QD concentration $0.4 \mathrm{nmol} / \mathrm{kg}$ bodyweight.

Abbreviations: QD, quantum dot; NS, not significant; PEG, polyethylene glycol.

not shown), whereas the quantum dots coated with noncrosslinked dendrimers were highly cytotoxic in concentrations $>50 \mathrm{nM}$.

The cytotoxicity of quantum dots coated with noncrosslinked dendrimers can be explained with the intrinsic instability of the micelle type of dendrimer coat. The micelle structure is a result of weak hydrophobic interactions, and its partial destruction in the cell suspension is highly possible. Thus, cytotoxic monomers can be released into the intracellular and extracellular environment. Several groups have also shown that cationic PAMAM dendrimers are cytotoxic in their monomer form. ${ }^{33-38}$

The micelle type of organic coat could also be destroyed in the bloodstream, and the monomers can have side effects on blood pressure and heart rate (Table 1 and Table 2). It has been established in vitro that the cationic PAMAM dendrimers modulate the release of nitric oxide, one of the major vasodilators in vivo, ${ }^{39}$ while the anionic PAMAM-COOH dendrimers significantly reduce this process. ${ }^{36}$ In our study, we observed vasodilatation of the brain arterioles and venuoles after injection of quantum dots coated by non-crosslinked positively charged dendrimers (Table 1). The quantum dots encapsulated

Table 5 Effect of silica-shelled CdSe/ZnS QDs (conjugated with PEG I I00) on cell viability in vitro (\% from control)

\begin{tabular}{llllll}
\hline Cell & \multicolumn{1}{l}{$\mathbf{1 0} \mathbf{n M}$} & $\mathbf{5 0} \mathbf{n M}$ & \multicolumn{1}{l}{$\mathbf{1 0 0} \mathbf{n M}$} & $\mathbf{2 0 0} \mathbf{n M}$ & $\mathbf{5 0 0} \mathbf{n M}$ \\
line & QD & QD & QD & QD & QD \\
\hline Jurkat & $101 \pm 9$ & $99 \pm 7$ & $100 \pm 7$ & $103 \pm 10$ & $98 \pm 7$ \\
K562 & $100 \pm 5$ & $102 \pm 8$ & $98 \pm 5$ & $96 \pm 8$ & $98 \pm 7$ \\
A549 & $98 \pm 4$ & $101 \pm 5$ & $98 \pm 7$ & $98 \pm 9$ & $96 \pm 10$ \\
HeLa & $102 \pm 6$ & $103 \pm 4$ & $99 \pm 9$ & $98 \pm 5$ & $96 \pm 8$ \\
\hline
\end{tabular}

Notes: The cell suspension $\left(5 \times 10^{5}\right.$ cells $\left./ \mathrm{mL}\right)$ was incubated with QDs for 24 hours in a humidified atmosphere, and cell viability was analyzed by flow cytometry. Cell viability in the absence of QDs was considered to be $100 \%$ (control). The data are means \pm standard deviations from six independent experiments.

Abbreviations: QD, quantum dot; PEG, polyethylene glycol. in crosslinked carboxyl-functionalized dendrimers did not manifest such effects (Table 2). The encapsulated organic coat is stable because of covalent bonds, and release of monomers is impossible without a specific metabolic pathway.

It is widely accepted that the cytotoxicity of dendrimers is due to their high cellular permeability and colocalization in the mitochondria and lysosomes. ${ }^{35,40}$ We investigated the effect of both quantum dot probes on the mitochondrial potential $\left(\Delta \psi_{\mathrm{m}}\right)$ of living cells (Figure 4). The mitochondrial potential is one of the major markers for induction of apoptosis. For this purpose, we used the quantum $\operatorname{dot}^{485}$ and TMRE $\left(\lambda_{\text {em }}=575 \mathrm{~nm}\right)$ as a fluorescent sensor. The fluorescence of TMRE changes proportionate to mitochondrial potential. Loss of the mitochondrial potential is accompanied by a significant decrease or total loss of TMRE fluorescence. ${ }^{26}$ The kinetic curves in Figure 4A show that quantum dots coated with non-crosslinked PAMAM dendrimers induce depolarization of the mitochondrial membrane and loss of the mitochondrial potential in living cells. The quantum dots encapsulated in crosslinked dendrimers did not affect the mitochondrial potential.

It is widely accepted that loss of mitochondrial potential induces expression of cytochrome $\mathrm{c}$ and apoptotic peptidaseactivating factor 1 . This leads to activation of caspases, induction of apoptosis, and cell death. ${ }^{41-43}$ This molecular mechanism could explain, at least partially, the cytotoxic effect of quantum dots coated with non-crosslinked PAMAM dendrimers (Figure 4B).

\section{Biocompatibility of silica-shelled quantum dots}

Silica materials are one of the most bioinert and biocompatible materials for coating. It has been found that silica nanoparticles with diameters below $50 \mathrm{~nm}$ do not activate macrophages ${ }^{44-46}$ and should not induce an immune response after intravenous injection. However, silica shells do not provide sufficiently high solubility of quantum dots in highsalt physiological fluids, such as saline solution, phosphatebuffered saline, blood, and plasma. ${ }^{47}$

In 2006, we developed silica-shelled single $\mathrm{CdSe} / \mathrm{ZnS}$ quantum dots with an average diameter of $17.42 \pm 2.12 \mathrm{~nm}$, a size distribution of about $12 \%$, and a quantum yield of $30 \%-45 \%$ (depending on the size of the silica-shelled quantum dots, and measured in distilled water, Figure 5). ${ }^{48}$ However, without PEGylation, these amino-functionalized nanoparticles possessed good colloidal stability in distilled water and low-salt buffer, but not in saline solution, phosphate-buffered saline, or body fluids. For example, if mice were inoculated intranasally with non-PEGylated 


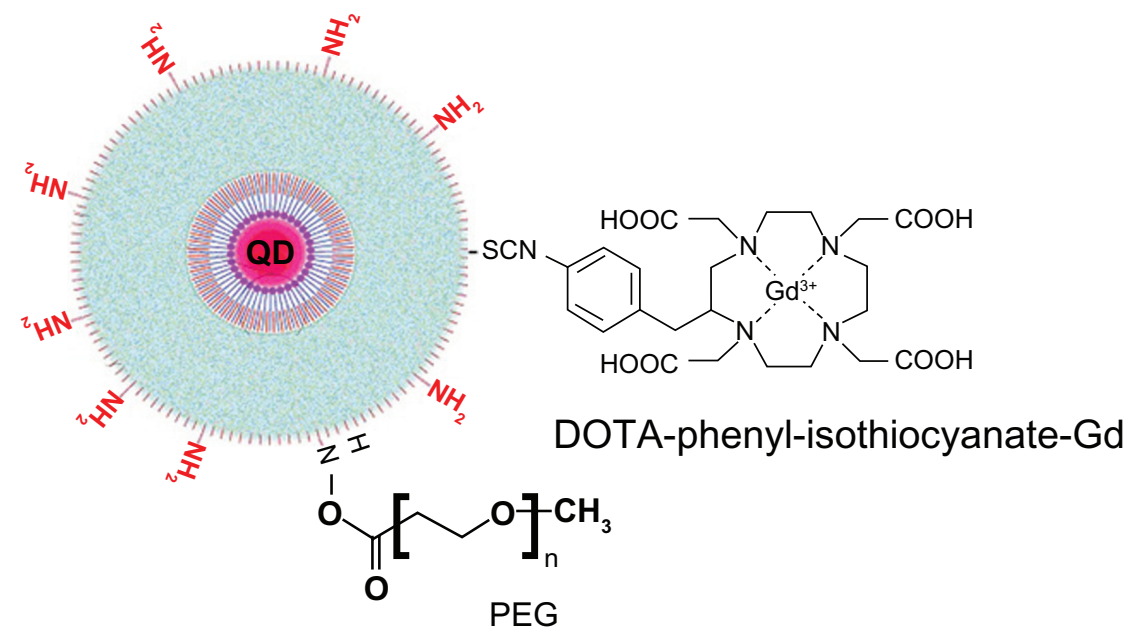

Figure 8 Model structure of PEGylated multimodal silica-shelled quantum dots. ${ }^{48}$

Note: Reprinted with permission from Zhelev Z, Ohba H, Bakalova R. Single quantum dot-micelles coated with silica shell as potentially non-cytotoxic fluorescent cell tracers. J Am Chem Soc. 2006; 128:6324-6325. Copyright 2006 American Chemical Society.

Abbreviations: PEG, polyethylene glycol; DOTA, tetraazacyclododecanetetraacetic acid.

silica-shelled quantum dots, we observed a lot of aggregates in the nasal mucosa (Figure 6). Therefore, PEGylation and stabilization were necessary before these nanoparticles could be applied for imaging in vivo and especially in the case of intravenous and intranasal administration. The PEGylated silica-shelled quantum dots possessed high colloidal stability and did not aggregate in high-salt physiological fluids (eg, $100 \mathrm{mM}$ phosphate-buffered saline and plasma).

PEG1100-grafted silica-shelled quantum dots injected intravenously into the rat and brain vasculature were visualized using two-photon excited fluorescent microscopy (Figure 7). The images were obtained at $\lambda_{\text {ex }}=810 \mathrm{~nm}$ and an emission filter of $525 \pm 50 \mathrm{~nm}$, with scanning in the horizontal plane at a depth of $150 \mu \mathrm{m}$ from the surface of the skull.

Table 6 Spectral characteristics of PEG I I00-grafted multimodal silica-shelled QDs

\begin{tabular}{ll}
\hline Spectral characteristic & Value \\
\hline QY in I0 mM PBS, pH 7.4 (\%) & $35-48$ \\
QY in I00 mM PBS, pH 7.4 (\%) & $32-45$ \\
Longitudinal relaxation time, $T_{1}(\mathrm{msec})$ & $293.4 \pm 23.5$ \\
Transverse relaxation time, $\mathrm{T}_{2}(\mathrm{msec})$ & $128.5 \pm 5.3$ \\
\hline
\end{tabular}

Notes: $T_{1}$ and $T_{2}$ data are means \pm standard deviations from six independent experiments. $T_{1}$ and $T_{2}$ data were calculated at a $Q D$ concentration of $500 \mathrm{nM}$. The magnetic resonance imaging measurements were performed in a $4.7 \mathrm{~T}$ magnet (General Electric, Fairfield, CT) interfaced to a Bruker Avance console (Bruker Medical GmbH, Germany). A 30 mm diameter Litz coil (Doty Scientific Inc, Columbia, SC) was used for measurement of the samples. The sample temperature was maintained at room temperature (approximately $22-24^{\circ} \mathrm{C}$ ). The measurements were performed in the following order: $\mathrm{T}_{1}$-weighted imaging using conventional spin echo sequence; multiecho spin echo imaging for $\mathrm{T}_{2}$ calculations; and inversion recovery

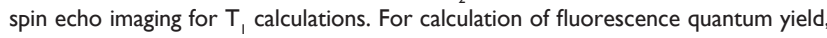
the spectrally integrated emission of particle dispersion in different aqueous solutions was compared with the integrated emission of an ethanol solution of rhodamine $G$ (Fluka) of identical optical density $(<0.015)$ at an excitation wavelength of $365 \mathrm{~nm}$. Abbreviations: QD, quantum dot; PEG, polyethylene glycol; PBS, phosphatebuffered saline; QY, quantum yield.
The fluorescent contrast was constant during 30 minutes of scanning. The PEG1100-grafted silica-shelled quantum dots gave clear images even at high concentrations $(2.5 \mathrm{nmol}$ quantum dots/kg bodyweight, Figure 7 ). On the other hand, $0.2 \mathrm{pmol}$ quantum dots $/ \mathrm{kg}$ bodyweight was enough
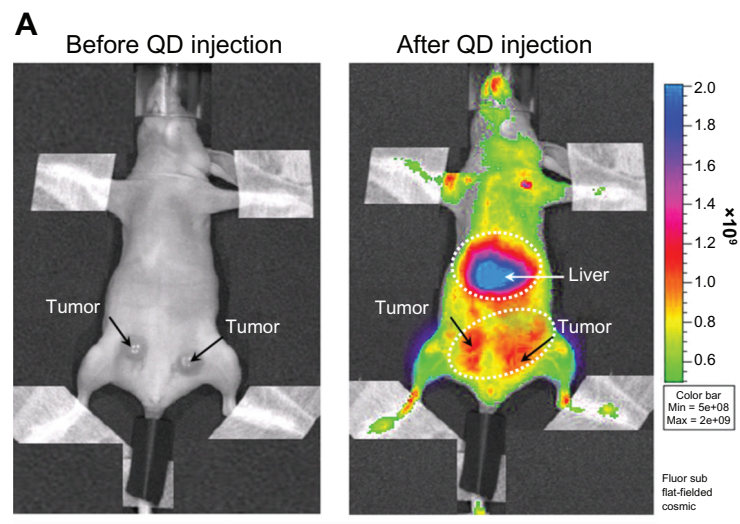

B

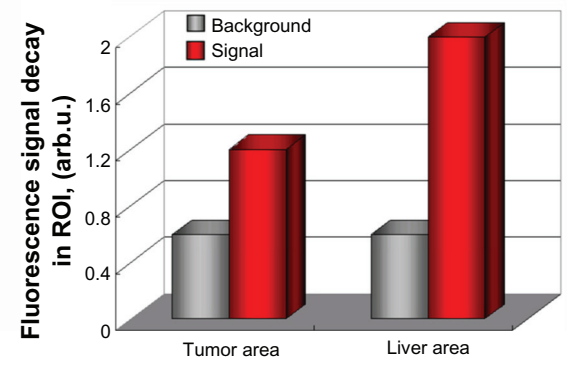

Figure 9 (A) Fluorescent imaging of tumor by angiogenesis in the anesthetized mouse injected intravenously with PEGI I00-grafted multimodal QD ${ }^{655}(1.6 \mathrm{nmol} / \mathrm{kg}$ bodyweight, single dose). Dashed lines indicate liver area and tumor area (including angiogenic network). The images were obtained 15 minutes after injection using an IVIS ${ }^{\circledR}$ imaging system, with excitation at $450 \pm 30 \mathrm{~nm}$ and emission at $650 \mathrm{~nm}$ (DsRed filter). The images were obtained on day 10 after inoculation $\left(1 \times 10^{5}\right.$ cells in $\left.10 \mu \mathrm{L}\right)$. (B) Fluorescence intensity in tumor area, liver area, and other parts of the body (background fluorescence) after intravenous injection of PEGII00-grafted multimodal QD ${ }^{655}$ ( $1.6 \mathrm{nmol} / \mathrm{kg}$ bodyweight, single dose). Data were calculated from the images in $\mathbf{A}$. Abbreviations: QD, quantum dot; PEG, polyethylene glycol. 
A Three days after inoculation (tumor diameter $\sim 2 \mathbf{~ m m}$ )
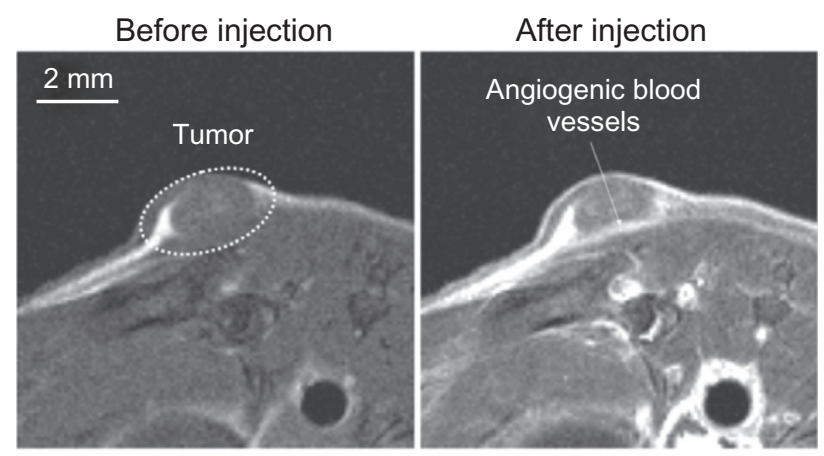

\section{B Ten days after inoculation (tumor diameter $\sim 6 \mathrm{~mm}$ )}

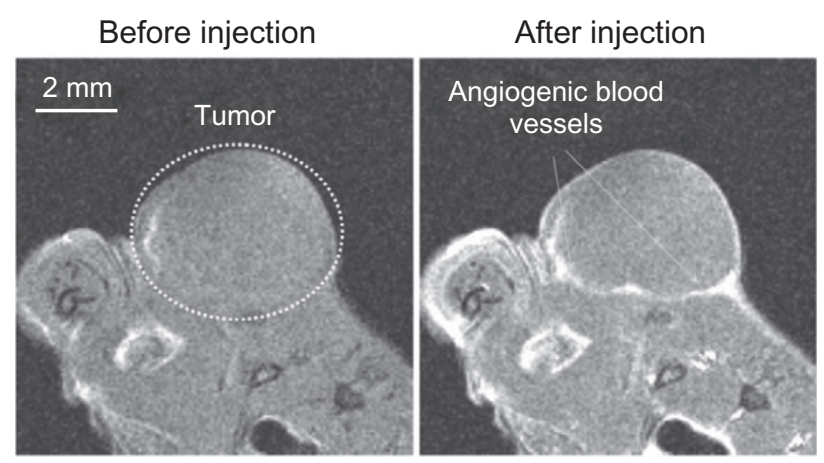

Figure 10 $\mathrm{T}_{\text {, }}$-weighted magnetic resonance images of colon cancer in the anesthetized mouse injected intravenously with PEGII00-grafted multimodal QD ${ }^{655}$ embedded with gadolinium ( $1 \mu \mathrm{mol} / \mathrm{kg}$ bodyweight, single dose). Dashed lines indicate tumor area (including angiogenic vasculature). The images were obtained immediately after injection, using 7.0 Tesla magnetic resonance imaging. Imaging parameters: spin echo sequence with fat suppression preparation pulse; repetition time $400 \mathrm{msec}$; echo time $9.574 \mathrm{msec}$; field of view $32 \times 32 \mathrm{~mm}$; matrix size $256 \times 256$; slice thickness $1.0 \mathrm{~mm}$; number of averages 4 .

Abbreviations: QD, quantum dot; PEG, polyethylene glycol.

to visualize the large-sized and middle-sized blood vessels at a depth of $150 \mu \mathrm{m}$. Increasing the concentration of the quantum dot probe, it was possible to visualize the arteries and veins at a depth of $600-700 \mu \mathrm{m}$. These quantum dots did not affect blood pressure or heart rate, and did not provoke vasodilatation or vasoconstriction up to 60 minutes after injection (Table 4). The PEGylated silica-shelled quantum dots were noncytotoxic in concentrations up to $500 \mathrm{nM}$, as determined in cultured cells (Table 5).

The PEG1100-grafted silica-shelled quantum dots ${ }^{655}$ were conjugated with DOTA $/ \mathrm{Gd}^{3+}$, and the probe was applied for multimodal imaging of cancer in mice. This is a classical scheme for the multimodal quantum dot probes developed by other researchers (Figure 8). ${ }^{1,4}$

The fluorescent and magnetic resonance imaging characteristics of our multimodal quantum dots are shown in Table 6. The fluorescent quantum yield was about $40 \%$ in high-salt buffer. The longitudinal and transverse relaxation times $\left(\mathrm{T}_{1}\right.$ and $\left.\mathrm{T}_{2}\right)$ were about $290 \mathrm{msec}$ and $120 \mathrm{msec}$, respectively.

The fluorescent images in Figure 9A show that the multimodal silica-shelled quantum dots visualized the tumor by angiogenesis. The experimental tumor was developed within 10 days after inoculation of Colon 32 cells in the left and right hind paws of mice. Fluorescence intensity in the tumor area was approximately three times higher than that in the surrounding tissues (Figure 9B). Maximum fluorescence intensity was detected in the liver area. It seems that these nanoparticles accumulated predominantly in the liver area within 90 minutes of their injection into the tail vein. Other authors have also reported that polymer-coated quantum dots accumulate predominantly in the liver, partially in the spleen, lung, and kidney, and are almost never observed in the heart and brain. ${ }^{49}$

The paramagnetic characteristics of the quantum dot probe also enabled visualization of tumors using magnetic resonance imaging (Figure 10). The short longitudinal relaxation time $\left(\mathrm{T}_{1}\right)$ of gadolinium in the silica spheres allowed visualization of the tumor on the third day after inoculation, when tumor size was about $2 \mathrm{~mm}$ in diameter and the angiogenic network was not well developed.

\section{Conclusion}

The data presented here show that the type and structure of organic/bioorganic shells of quantum dots are crucial for their colloidal stability and solubility in physiological fluids, and their biocompatibility and cytotoxicity. All these parameters have to be identified and controlled before application of organic-coated quantum dots for in vivo imaging. CdSe/ $\mathrm{ZnS}$ quantum dots, coated with non-crosslinked PAMAM dendrimers and amino-functionalized, are cytotoxic and nonbiocompatible. These quantum dots have side effects after intravenous administration in healthy animals, ie, decreased blood pressure and heart rate, as well as vasodilatation. Presumably this is as a result of instability of the dendrimer coat in the bloodstream and release of free monomers, inducing cytotoxic mechanisms in the organism. These quantum dots are not appropriate for in vivo imaging of vasculature structure, because the nanoparticles seem to penetrate the vessels, affecting the quality of the images.

$\mathrm{CdSe} / \mathrm{ZnS}$ quantum dots encapsulated in crosslinked carboxyl dendrimers have low cytotoxicity and comparatively good biocompatibility in concentrations up to $0.3 \mathrm{nmol} / \mathrm{kg}$ bodyweight. This quantum dot probe is appropriate for in vivo imaging. PEGylation is not required to increase the halflife of dendrimer-coated quantum dots in the bloodstream. 
However, PEGylation is an indispensable step in development of quantum dot probes for in vivo imaging, based on silica-shelled quantum dots. Non-PEGylated and aminofunctionalized silica-shelled quantum dots have low colloidal stability in high-salt physiological fluids, which is accompanied with rapid aggregation. The aggregates could induce activation of macrophages and a nonspecific immune response in vivo. The conjugation of silica-shelled quantum dots with PEG1100 increases their half-life in the circulation without significant enhancement of their size. PEG1100-grafted silicashelled quantum dots are appropriate for visualization of blood vasculature and circulation in vivo, using two-photon excited fluorescent microscopy. In concentrations up to $2.5 \mathrm{nmol} / \mathrm{kg}$ bodyweight injected intravenously, these quantum dots do not affect physiological variables, eg, blood pressure, heart rate, and blood vessel diameter. Using these quantum dots, it was possible to visualize capillaries, which makes them appropriate for investigation of mediators of vasoconstriction, vasodilatation, and brain circulation in intact animals in vivo.

It should be noted that our results are related to use of quantum dots for structural fluorescent imaging of blood vessels and tumors. Quantum dot probes with sensing properties also have potential for functional imaging diagnostics in vivo. ${ }^{50}$

\section{Acknowledgments}

We thank Dr Kazuto Masamoto, Center for Frontier Science and Engineering, University of Electrocommunications, Japan, for his help with the two-photon fluorescent imaging, and Ms Sayaka Shibata, Molecular Imaging Center, National Institute of Radiological Sciences, Chiba, Japan, for her assistance with the animal magnetic resonance imaging experiments. This research is partially funded by the Japan Society for the Promotion of Science (JSPS) through the "Funding Program for World-Leading Innovative R\&D on Science and Technology (FIRST Program)," initiated by the Council for Science and Technology Policy (CSTP), as well as by the Grand-in-aid "Kakenhi."

\section{Disclosure}

The authors report no conflicts of interest in this work.

\section{References}

1. Michalet X, Pinaud FF, Bentolila LA, et al. Quantum dots for live cells, in vivo imaging, and diagnostics. Science. 2005;307:538-544.

2. Larson DR, Zipfel WR, Williams RM, et al. Water-soluble quantum dots for multiphoton fluorescence imaging in vivo. Science. 2003; 300:1434-1437.

3. Kosaka N, McCann TE, Mitsunaga M, Choyke PL, Kobayashi H. Real-time optical imaging using quantum dot and related nanocrystals. Nanomedicine (Lond). 2010;5:765-776.
4. Bakalova R, Zhelev Z, Aoki I, Kanno I. Designing quantum dot probes. Nat Photonics. 2007;1:487-489.

5. Romberg B, Hennink WE, Storm G. Sheddable coatings for longcirculating nanoparticles. Pharm Res. 2008;25:55-71.

6. Hagens WI, Oomes AG, De Jong WH, Cassee FR, Sips AJ. What do we need to know about kinetic properties of nanoparticles in the body? Regul Toxicol Pharmacol. 2007;49:217-229.

7. Longmire M, Choyke PL, Kobayashi H. Clearance properties of nano-sized particles and molecules as imaging agents: Considerations and caveats. Nanomedicine. 2008;3:703-717.

8. Allermann E, Brasseur N, Benrezzak O, et al. PEG-coated poly(lactic acid) nanoparticles for the delivery of xehadecafluoro zinc phthalocyanine to EMT-6 mouse mammary tumours. J Pharm Pharmacol. 1995;47:382-387.

9. Leroux JC, DeJaeghere F, Anner B, Doelker E, Gumy R. An investigation of the role of plasma and serum opsonins on the internalization of biodegradable poly(D,L-lactic acid) nanoparticles by human monocytes. Life Sci. 1995;57:695-703.

10. Heller J. Controlled release of biologically active compounds from bioerodible polymers. Biomaterials. 1980;1:51-57.

11. Buckles RG. Biomaterials for drug delivery systems. J Biomed Mater Res. 1983;17:109-128.

12. Laurencin CT, Pierre-Jacques HM, Langer R. Toxicology and biocompatibility considerations in the evaluation of polymeric materials for biomedical applications. Clin Lab Med. 1990;10:549-570.

13. Sidorov SN, Bronstein LM, Valetsky PM, et al. Stabilization of metal nanoparticles in aqueous medium by polyethyleneoxide-polyethyleneimine block copolymers. J Colloid Interface Sci. 1999;212: 197-211.

14. Crooks RM, Zhao M, Sun L, Chechik V, Yeung LK. Dendrimerencapsulated metal nanoparticles: Synthesis, characterization, and application to catalysis. Acc Chem Res. 2001;34:181-190.

15. Van der Klauw MM, Wilson JH, Stricker H. Drug-associated anaphylaxis: 20 years of reporting in the Netherlands (1974-1994) and review of the literature. Clin Exp Allergy. 1996;26:1355-1363.

16. Otsuka H, Nagasaki Y, Kataoka K. PEGylated nanoparticles for biological and pharmaceutical applications. Adv Drug Deliv Rev. 2003;55: 403-419.

17. Woodle MC. Controlling liposome blood clearance by surface-grafted polymers. Adv Drug Deliv Rev. 1998;32:139-152.

18. Torchilin VP. Micellar nanoparticles: Pharmaceutical perspectives. Pharm Res. 2007;24:1-16.

19. Peng ZA, Peng X. Formation of high-quality CCdTe, CdSe, and CdS nanocrystals using CdO as precursor. J Am Chem Soc. 2001;23: 183-184.

20. Zlateva G, Zhelev Z, Bakalova R, Kanno I. Precise size-control and synchronized synthesis of six colours of CdSe quantum dots in a slow-increasing temperature gradient. Inorg Chem. 2007;46: 6212-6214.

21. Yu WW, Qu L, Guo W, Peng X. Experimental determination of the excitation coefficient of CdTe, CdSe and CdS nanocrystals. Chem Mater. 2003;15:2854-2860.

22. Bakalova R, Zhelev Z, Aoki I, Ohba H, Kanno I. Silica-shelled single quantum dot micelles as imaging probes with dual or multimodality. Anal Chem. 2006;78:5925-5932.

23. Wu X, Liu H, Haley KN, Treadway JA, et al. Immunofluorescent labelling of cancer marker Her2 and other cellular targets with semiconductor quantum dots. Nat Biotechnol. 2003;21:41-46.

24. Hermanson GT. Bioconjugate Techniques. New York, NY: Academic Press; 1996.

25. Bakalova R, Zhelev Z, Aoki I, et al. Multimodal silica-shelled quantum dots: Direct intracellular delivery, photosensitization, toxic, and microcirculation effects. Bioconjug Chem. 2008;19: $1135-1142$.

26. Wong A, Cortopassi GA. High-throughput measurement of mitochondrial membrane potential in a neural cell line using a fluorescence plate reader. Biochem Biophys Res Commun. 2002;298:750-754. 
27. Kitchens KM, El-Sayed MEH, Ghandehari H. Transepithelial and endothelial transport of poly(amidoamine) dendrimers. Adv Drug Deliv Rev. 2005;57:2163-2176.

28. Medina SH, El-Sayed ME. Dendrimers as carriers for delivery of chemotherapeutic agents. Chem Rev. 2009;109:3141-3157.

29. Nadjwade BK, Bechra HM, Derkar GK, Manvi FV, Nadjwade VK. Dendrimers: Emerging polymers for drug-delivery systems. Eur $J$ Pharm Sci. 2009;38:185-196.

30. Paleos CM, Tziveleka LA, Sideratou Z, Tsiourvas D. Gene delivery using functional dendritic polymers. Expert Opin Drug Deliv. 2009; 6:27-38.

31. Samad A, Alam MI, Saxena K. Dendrimers: A class of polymers in the nanotechnology for the delivery of active pharmaceuticals. Curr Pharm Des. 2009; 15:2958-2969.

32. Derfus AM, Chan WCW, Bhatia SN. Probing the citotoxycity of semiconductor quantum dots. Nano Lett. 2009;4:11-18.

33. Kolhatkar RB, Kitchens KM, Swaan PW, Ghandehari H. Surface acetylation of polyamidoamine (PAMAM) dendrimers decreases cytotoxicity while maintaining membrane permeability. Bioconjug Chem. 2007;18: 2054-2060.

34. Nam NY, Hahn HJ, Nam K, et al. Evaluation of generation 2, 3 and 4 arginine modified PAMAM dendrimers for gene delivery. Int J Pharm. 2008;363:199-205.

35. Thomas TP, Majoros I, Kotlyar A, Mullen D, Holl MM, Baker JR Jr. Cationic poly(amidoamine) dendrimer induces lysosomal apoptotic pathways at theoretically relevant concentrations. Biomacromolecules. 2009;10:3207-3214.

36. Wang W, Xiong W, Wan J, Sun X, Xu H, Yang X. The decrease of PAMAM dendrimer-induced cytotoxicity by PEG-ylation via attenuation of oxidative stress. Nanotechnology. 2009;20:105103.

37. Wang B, Navath RS, Romero R, Kannan S, Kannan R. Anti-inflammatory and anti-oxidant activity of anionic dendrimer-N-acetyl cysteine conjugates in activated microglial cells. Int J Pharm. 2009;377:159-168.
38. Yellepeddi VK, Kumar A, Palakurthi S. Surface modified poly(amidoamine) dendrimers as diverse nanomolecules for biomedical applications. Expert Opin Drug Deliv. 2009;6:835-850.

39. Stanko NA, Schoenfisch MN. Dendrimers as a scaffold for nitric oxide release. J Am Chem Soc. 2006;128:8265-8271.

40. Saovapakhiran A, D'Emanuele A, Attwood D, Penny J. Surfacemodification of PAMAM dendrimers modulates the mechanism of cellular internalization. Bioconjug Chem. 2009;20:693-701.

41. Adams JM, Cory S. Apoptosomes: Engines of caspase activation. Curr Opin Cell Biol. 2002;14:715-720.

42. Anichini A, Mortarini R, Sensi M, Zanon M. APAF-1 signalling in human melanoma. Cancer Lett. 2006;238:168-179.

43. Caroppi P, Sinibaldi F, Fiorucci L, Santucci R. Apoptosis and human diseases: Mitochondrion damage and lethal role of released cytochrome c as proapoptotic protein. Curr Med Chem. 2009;16:4058-4065.

44. Choi J, Burns AA, Williams RM, et al. Core-shell silica nanoparticles as fluorescent labels for nanomedicine. J Biomed Opt. 2007;12:064007.

45. Cho M, Cho WS, Choi M, et al. The impact of size on tissue distribution and elimination by single intravenous injection of silica nanoparticles. Toxicol Lett. 2009;189:177-183.

46. Waters KM, Masiello LM, Zangar RC, et al. Macrophage responses to silica nanoparticles are highly conserved across particle sizes. Toxicol Sci. 2009;107:553-569.

47. Dubertret B, Skourides P, Norris DJ, Noireaux V, Brivanlou AH, Libchaber A. In vivo imaging of quantum dots encapsulated in phospholipid micelles. Science. 2002;98:1759-1762.

48. Zhelev Z, Ohba H, Bakalova R. Single quantum dot-micelles coated with silica shell as potentially non-cytotoxic fluorescent cell tracers. $J \mathrm{Am}$ Chem Soc. 2006;128:6324-6325.

49. Choi HS, Liu W, Misra P, et al. Renal clearance of quantum dots. Nat Biotechnol. 2007;25:1165-1170.

50. Bakalova R. Fluorescent molecular sensors and multi-photon microscopy in brain studies. Brain Res Bull. 2007;73:150-153. 


\section{Supplementary data}

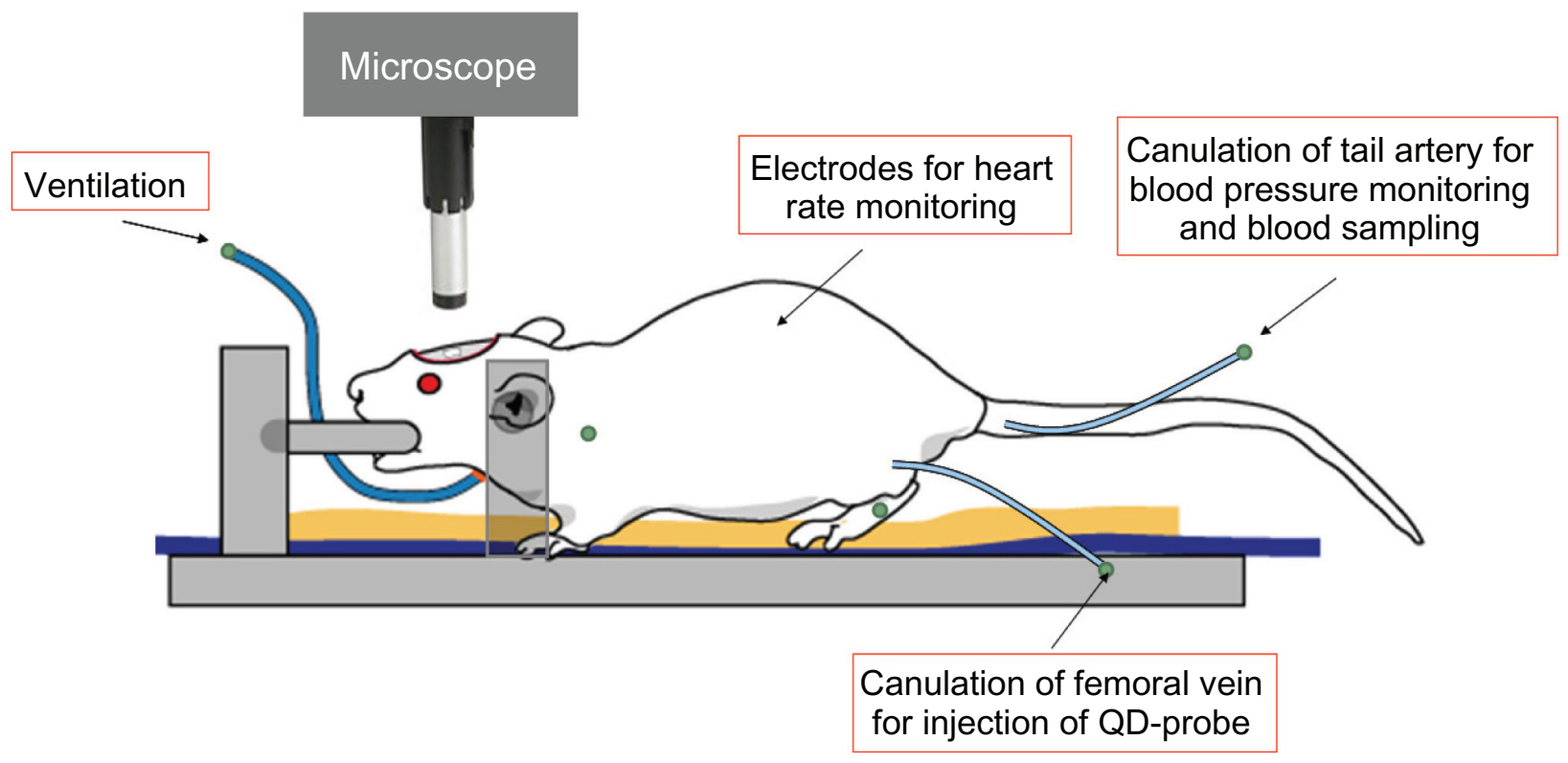

Figure SI Experimental scheme of imaging of two-photon excited fluorescence in rats. Abbreviation: QD, quantum dot.

Table SI Physiological characteristics of rats before and after intravenous injection of polyamidoamine $\mathrm{Cl} 2 \mathrm{dendrimer} 0 . \mathrm{Immol} / \mathrm{kg}$ bodyweight

\begin{tabular}{lccc}
\hline Parameters & Before injection & About 20 minutes after injection & P value \\
\hline Mean arterial blood pressure $(\mathrm{mmHg})$ & $114.0 \pm 5.5$ & $68.3 \pm 8.5$ & $<0.01$ \\
Heart rate (beats per minute) & $392 \pm 24$ & $317 \pm 18$ & $<0.05$ \\
Mean diameter of detected arteries $(\mu \mathrm{m})$ & $29 \pm 7$ & $39 \pm 1 \mathrm{I}$ (vasodilatation) & $<0.05$ \\
Mean diameter of detected veins $(\mu \mathrm{m})$ & $42 \pm 21$ & $47 \pm 14$ (vasodilatation) & $<0.05$ \\
\hline
\end{tabular}

Notes: Data are means \pm standard deviations from five independent experiments. The experimental conditions are the same as in Table I.

Table S2 Effect of PAMAM CI 2 dendrimers on cell viability in vitro (\% from control)

\begin{tabular}{lllr}
\hline Cell line & $\mathbf{5 0} \mathbf{n M}$ dendrimer & 100 $\mathbf{n M}$ dendrimer & $\mathbf{5 0 0} \mathbf{n M}$ dendrimer \\
\hline Jurkat & $65 \pm 5$ & $37 \pm 4$ & $8 \pm 4$ \\
K562 & $57 \pm 9$ & $31 \pm 5$ & $3 \pm 1$ \\
A549 & $68 \pm 9$ & $40 \pm 8$ & $5 \pm 1$ \\
HeLa & $70 \pm 8$ & $42 \pm 4$ & $12 \pm 4$ \\
\hline
\end{tabular}

Notes: The cell suspension $\left(5 \times 10^{5}\right.$ cells $\left./ \mathrm{mL}\right)$ was incubated with dendrimers over 24 hours in a humidified atmosphere, and cell viability was analyzed by flow cytometry Cell viability in the absence of dendrimer was considered 100\% (control). The data are means \pm standards deviation from six independent experiments. 
Table S3 Effect of water-soluble amino-functionalized CdSe/ZnS QD ${ }^{485}$ without additional organic shell on cell viability in vitro (\% from control)

\begin{tabular}{llcccc}
\hline Cell line & I0 nM QD & 50 nM QD & 100 nM QD & 200 nM QD & 500 nM QD \\
\hline Jurkat & $104 \pm 5$ & $98 \pm 8$ & $100 \pm 2$ & $97 \pm 6$ & $96 \pm 8$ \\
K562 & $100 \pm 3$ & $101 \pm 5$ & $103 \pm 4$ & $97 \pm 5$ & $95 \pm 5$ \\
A549 & $100 \pm 6$ & $103 \pm 5$ & $99 \pm 8$ & $100 \pm 4$ & $97 \pm 4$ \\
HeLa & $102 \pm 4$ & $98 \pm 7$ & $97 \pm 6$ & $98 \pm 5$ & $94 \pm 9$ \\
\hline
\end{tabular}

Notes: The cell suspension $\left(5 \times 10^{5}\right.$ cells $\left./ \mathrm{mL}\right)$ was incubated with QDs within 24 hours at humidified atmosphere, and cell viability was analyzed by flow cytometry. The cell viability in absence of QD was considered $100 \%$ (control). Data are means \pm standard deviations from six independent experiments.

Abbreviation: QD, quantum dot.

\section{Publish your work in this journal}

The International Journal of Nanomedicine is an international, peerreviewed journal focusing on the application of nanotechnology in diagnostics, therapeutics, and drug delivery systems throughout the biomedical field. This journal is indexed on PubMed Central, MedLine, CAS, SciSearch $\AA$, Current Contents ${ }^{\circledR} /$ Clinical Medicine,
Journal Citation Reports/Science Edition, EMBase, Scopus and the Elsevier Bibliographic databases. The manuscript management system is completely online and includes a very quick and fair peer-review system, which is all easy to use. Visit http://www.dovepress.com/ testimonials.php to read real quotes from published authors. 